\title{
Thrombin Is an Important Mediator of Platelet Aggregation in Stenosed Canine Coronary Arteries with Endothelial Injury
}

\author{
John F. Eidt, Paul Allison, Sharon Noble, Juliet Ashton, Paolo Golino, Janice McNatt, \\ L. Maximilian Buja, and James T. Willerson \\ Departments of Medicine (Cardiology Division), Pathology and Surgery at the University of Texas \\ Southwestern Medical Center at Dallas, Texas 75235
}

\begin{abstract}
Cyclic variations in coronary blood flow (CFVs) in dogs with experimental coronary artery stenosis and endothelial injury appear to result primarily from the aggregation of platelets at the site of stenosis followed by dislodgement and distal embolization. Using this canine model, we tested the hypotheses: (a) that thrombin is an important mediator of CFVs in dogs with coronary stenoses and endothelial injury; (b) that inhibition of thrombin with heparin, or MCI-9038, a selective thrombin inhibitor, abolishes CFVs in this model; and (c) that abolition of CFVs by thrombin inhibition is time dependent. CFVs, produced in open-chest dogs by placing a flow-reducing plastic constrictor around the left anterior coronary artery, were monitored for either $30 \mathrm{~min}$ (group I) or $3 \mathrm{~h}$ (group II) before treatment with either heparin or 4-methyl-1-( $N^{2}-$-(3-methyl1,2,3,4-tetrahydro-8-quinolinyl (MCI-9038). In group I, cyclic flow variations were abolished by heparin in 12 of 18 dogs and by MCI-9038 in 5 of 7 dogs. In group II, cyclic flow variations were not abolished by heparin in any of seven dogs and were abolished by MCI-9038 in only one of seven dogs. Thus, (a) thrombin appears to be an important mediator of cyclic flow variations in dogs with coronary artery stenosis and endothelial injury and (b) inhibition of thrombin abolishes CFVs after short but not prolonged periods of CFVs.
\end{abstract}

\section{Introduction}

Platelet-mediated obstruction of stenotic coronary arteries with damaged endothelium may be an important factor in certain occlusive coronary disease states (1-6). Using a welldefined canine model of in vivo platelet aggregation described originally by Folts et al. (7), we have shown that $\operatorname{TXA}_{2}(8,9)$ and serotonin (10-12) are important mediators of platelet aggregation and that the inhibition of serotonin receptor activation (10-12) or the inhibition of TXA $\mathrm{A}_{2}$ synthesis (8) or receptor activation (9) prevents cyclic coronary blood flow variations (CFVs) ${ }^{1}$ in most cases. We have also questioned the role of other mediators of platelet aggregation in causing cyclic

Address James T. Willerson, Chief of Cardiology, University of Texas Southwestern Medical Center, 5323 Harry Hines Blvd., Dallas, TX 75235.

Received for publication 1 July 1988 and in revised form 28 February 1989.

1. Abbreviations used in this paper: ACT, activated clotting time; aPTT, activated partial thromboplastia time; ATIII, antithrombin III; CFV, coronary flow variations; MCI-9038, 4-methyl-1-[ $N^{2}-[(3-$ methyl-1,2,3,4-tetrahydro-8-quinolinyl.

J. Clin. Invest.

(c) The American Society for Clinical Investigation, Inc.

0021-9738/89/07/0018/10 $\$ 2.00$

Volume 84, July 1989, 18-27 flow variations. One such mediator is the serine protease, thrombin.

Thrombin is the central bioregulatory enzyme in hemostasis (13). It is a potent activator of platelets either alone or in synergism with other agents (14). It is responsible for the conversion of fibrinogen to fibrin and for the activation of coagulation Factors V, VIII, and XIII (13). Thrombin may interact directly with the vessel wall, causing vasoconstriction $(15,16)$ and may mediate leukocyte adherence (17). Mathematical models have predicted that thrombin, but not ADP or TXA is present in sufficient concentration at the site of endovascular injury to initiate the first wave of platelet aggregation (18). It was our objective to test the effect of thrombin inhibition on the occurrence of platelet-dependent CFVs in dogs with coronary artery stenosis and endothelial injury. It is possible to inhibit thrombin either indirectly with heparin or directly with a synthetic thrombin inhibitor. The primary action of heparin is to accelerate the activity of the circulating anticoagulant, antithrombin III (ATIII) (19). Heparin may also have thrombin inhibitory activity independent of ATIII (20). MCI-9038 (4-methyl-1-[ $N^{2}$-[(3-methyl-1,2,3,4-tetrahydro-8-quinolinyl) sulfonyl]-L-arginyl]-2-piperidinecarboxylic acid) (obtained from Mitsubishi Chemical Industries, Tokyo, Japan) is a potent, highly selective inhibitor of thrombin whose effect is independent of ATIII $(21,22)$. We relied upon the ability of heparin or MCI-9038 to inhibit thrombin to test the hypotheses: (a) that thrombin is an important mediator of platelet aggregation and resultant CFVs in a canine model of coronary stenosis and endothelial injury; $(b)$ that inhibition of thrombin abolishes CFVs in this model; and (c) the abolition of CFVs by thrombin inhibition with heparin or MCI-9038 is time dependent.

\section{Methods}

Surgical preparation. 39 mongrel dogs of either sex, weighing 20-40 $\mathrm{kg}$, were anesthetized with $30 \mathrm{mg} / \mathrm{kg}$ sodium pentobarbital and ventilated with a mechanical respirator (Harvard Apparatus Co., Natick, MA). A heating pad was used to maintain body temperature at $38^{\circ} \mathrm{C}$. Carotid arterial and jugular venous catheters were inserted through a neck incision. A left fifth intercostal space thoracotomy was made and the heart was suspended in a pericardial cradle. A 2-cm segment of the left anterior descending coronary artery was gently isolated. An ultrasonic flow probe (Doppler; Hartley Instruments, Houston, TX) (23) was placed around the proximal segment of the coronary artery to measure phasic and mean coronary blood flow. After a 30-min stabilization period, control values for heart rates, blood pressures, and phasic and mean coronary blood flows were recorded on an eight-channel recorder (model 7758; Hewlett-Packard, Palo Alto, CA). After injuring the endothelium by gently squeezing the artery with a cushioned forceps, a hard cylindrical constrictor was placed around the artery at the site of injury to reduce phasic coronary blood flow $\sim 50 \%$. CFVs were allowed to develop and continuously monitored according to the following experimental protocol.

Control group. Five dogs were instrumented as previously described. CFVs were allowed to develop and monitored continuously 
for $5 \mathrm{~h}$. Placebo injections of normal saline $(50 \mathrm{ml})$ were administered every $30 \mathrm{~min}$. Record was made of the heart rates, blood pressures, frequency of CFVs, and the severity of CFVs as indicated by the nadir coronary blood flow.

Experimental groups. To assess the importance of time dependence on thrombin mediation of CFVs, two groups of dogs were defined by the duration of CFVs before thrombin inhibition. In group I $(n=25)$, CFVs were monitored for 30 min before treatment with either heparin sodium (24) (group IA) $(n=18)$ from beef lung (Upjohn Pharmaceuticals, Kalamazoo, MI) or MCI-9038 (group IB) $(n=7)$. In group II ( $n$ $=14$ ), CFVs were monitored for $3 \mathrm{~h}$ before treatment with either heparin (group IIA) $(n=7)$ or MCI-9038 (group IIB) $(n=7)$. The initial bolus doses of heparin ( 200 USP units $/ \mathrm{kg}$ i.v.) or MCI-9038 $(0.5$ $\mathrm{mg} / \mathrm{kg}$ i.v.) were repeated as needed to prolong the activated clotting time (ACT) to $350-400 \mathrm{~s}$ (control $=90-100 \mathrm{~s}$ ). The ACT was measured with an automated blood-coagulation timing device (Hemochron; International Technidyne Corp., Edison, NJ). Additional doses of either heparin or MCI-9038 were administered by either intravenous infusion or bolus to maintain a stable level of anticoagulation (ACT > $350 \mathrm{~s}$ ) throughout the remainder of the experiment. The heart rates and blood pressures were recorded and the frequency and severity of CFVs were determined before and after treatment with heparin or MCI-9038. The subsequent protocol for each dog depended upon the response to the initial treatment with heparin or MCI-9038.

CFVs abolished. If CFVs were abolished by treatment with heparin or MCI-9038, then observation and anticoagulation (ACT > $350 \mathrm{~s}$ ) were continued for at least $1 \mathrm{~h}$. In six group I dogs, observation and anticoagulation (ACT $>350 \mathrm{~s}$ ) were continued for $4 \mathrm{~h}$ and particular note was made of the reemergence of CFVs ("recurrent CFVs") after successful initial abolition with heparin.

CFVs not abolished. If CFVs were not abolished by the initial dose of heparin or MCI-9038 (sufficient to increase ACT > 350 s), then after a 30-min period of observation to ensure the persistence of the altered flow state, each dog was treated with either a $\mathrm{TXA}_{2} / \mathrm{PGH}_{2}$ receptor antagonist, SQ29548 (25) $(n=11)$ (E.R. Squibb Co., Princeton, NJ) $(0.2 \mathrm{mg} / \mathrm{kg}$ i.v. bolus) or placebo $(n=10)(50 \mathrm{ml}$ normal saline i.v. bolus). In dogs treated with the $\mathrm{TXA}_{2} / \mathrm{PGH}_{2}$ receptor antagonist, SQ29548, or placebo, observation was continued for at least $1 \mathrm{~h}$. The effect of treatment on the frequency and severity of CFVs was determined. If CFVs were not abolished by treatment with SQ29548, then each dog was also treated with a serotonin receptor antagonist, ketanserin $(26,27)$ (Janssen Research Pharmaceuticals, Beerse, Belgium) $(0.25 \mathrm{mg} / \mathrm{kg}$ i.v. bolus). The effect of treatment with the combination of SQ29548 and ketanserin was recorded during a 1-h period of observation.

Platelet aggregation. The effect of MCI-9038 or heparin on the aggregation of canine platelets in response to a panel of agonists was examined in a dual-channel aggregometer (Chronolog Instruments, Havertown, PA). Platelet-rich plasma (PRP) was prepared from whole blood collected into acid-citrate-dextrose (6:1) followed by centrifugation at $250 \mathrm{~g}$ for $20 \mathrm{~min}$ at $37^{\circ} \mathrm{C}$ as described by Aster et al. (28). Platelet-poor plasma (PPP) was obtained after centrifugation of platelet-rich plasma at $2,000 \mathrm{~g}$ for $10 \mathrm{~min}$. The platelet count was adjusted to $300,000 / \mathrm{ml}$. Washed canine platelets were prepared according to the method of Ardlie et al. (29). After centrifugation and washing twice, the platelets were suspended in Tyrode's solution (30) containing 2 $\mathrm{mM}$ calcium, $1 \mathrm{mM}$ magnesium, and $0.35 \%$ albumin. Blood samples were obtained during the control period before constrictor placement, after 30 min of CFVs, and after $3 \mathrm{~h}$ of CFVs.

In each case, a 450- $\mu$ l sample of either PRP or washed platelet suspension was transferred to a $1-\mathrm{ml}$ glass cuvette and stirred at 1,100 $\mathrm{rpm}$ for a 2 -min equilibration period at $37^{\circ} \mathrm{C}$. The agonists and range of final concentrations were ADP (Sigma Chemical Co., St. Louis, MO), 1-10 $\mu \mathrm{M}$; bovine collagen (Hormon-Chemie, Munich, West Germany), $1-10 \mu \mathrm{g} / \mathrm{ml}$; human thrombin, (Helena Laboratories, Beaumont, TX), 0.3-0.6 U/ml; and U46619, a synthetic $\mathrm{TXA}_{2}$ analogue (Upjohn Pharmaceuticals), 1-10 $\mu \mathrm{g} / \mathrm{ml}$. Transmission of light was expressed as a percent of the light transmitted through either PPP or tyrode solution. Each agonist was added to achieve a final volume of $500 \mu \mathrm{l}$. The minimal concentration of each agonist that resulted in a maximal increase in light transmission was selected for tests of the effect of MCI-9038 or heparin. In tests of platelet inhibition, MCI-9038 or heparin was added to the platelet sample and allowed to equilibrate for $60 \mathrm{~s}$ before addition of the agonist. The concentration of MCI-9038 or heparin required to produce a $50 \%$ reduction in maximal light transmission $\left(\mathrm{IC}_{50}\right)$ was determined for each agonist in both washed suspensions and PRP.

Thrombin- ${ }^{125}$ I-ATIII complex formation. To study the in vivo and in vitro effects of $\mathrm{MCI}-9038$ or heparin on dog thrombin activity, thrombin-ATIII complex formation was analyzed using ${ }^{125}$ I-ATIII. Complexes were detected by monitoring changes in the electrophoretic mobility of ${ }^{125}$ I-ATIII by SDS-PAGE (31). Electrophoretic mobilities of purified components and resulting complexes were determined for labeled and unlabeled ATIII, thrombin, heparin, and MCI-9038 according to the method of Rosenberg (32). To minimize the effect of enzymatic degradation of ATIII by thrombin, excess quantities of ATIII were maintained in all experiments (33). ATIII $(5 \mathrm{IU} / \mathrm{mg})(\mathrm{Hel}-$ ena Laboratories) was radiolabeled using ${ }^{125}$ I-sodium iodide (Amersham Corp., Arlington Heights, IL) and Iodogen (Pierce Chemical Co., Rockford, IL) and separated from free ${ }^{125}$ I-iodide by chromatography on Sephadex G-25 (Sigma Chemical Co.). The specific activity of the ${ }^{125}$ I-ATIII was 4-5 $\mu \mathrm{Ci} / \mu \mathrm{g}$ ATIII. Radiolabeled ATIII retained the same thrombin inhibitory activity as the starting material as determined by chromogenic assay (34). Blood samples were obtained from the jugular vein and from the left coronary artery distal to the site of injury to assess the effect of the constrictor on prothrombin activation. Dog plasma was immediately prepared from citrated blood $(9 \mathrm{vol}$ blood:1 vol 3.8\% sodium citrate) (Becton Dickinson \& Co., Rutherford, $\mathrm{NJ}$ ) by centrifugation (1,500 $\mathrm{g}$ for $20 \mathrm{~min})$. Thrombin was generated in citrated dog plasma by the addition of $\mathrm{CaCl}_{2}$ and tissue thromboplastin (Helena Laboratories). Additional experiments were performed using exogenous human alpha-thrombin (American Diagnostica, New York, NY) added to citrated dog plasma in the presence of ${ }^{125}$ I-ATIII and either MCI-9038 or heparin. After incubation for 20-30 min, reaction aliquots $\left(50-100 \times 10^{3} \mathrm{cpm}\right)$ were mixed with equal volumes of $0.1 \mathrm{M}$ Tris-phosphate ( $\mathrm{pH} 7.4$ ) containing $0.1 \%$ SDS, incubated for $1 \mathrm{~min}$ at $100^{\circ} \mathrm{C}$, and subjected to SDS-PAGE on 6\% gels. Reduction of disulfide bonds in some experiments was performed by addition of 3\% 2-mercaptoethanol (Sigma Chemical Co.) to the Tris-phosphate-SDS buffer. After electrophoresis, gels were sliced into $1-\mathrm{mm}$ segments and radioactivity was counted with a gammascintillation counter (Packard Instrument Co., Laguna Hills, CA). Prestained molecular weight markers (Bio-Rad Laboratories, Richmond, CA) were run on separate disc gels to estimate molecular weights of the protein bands from Coomassie brilliant blue-stained gels (Sigma Chemical Co.) of unlabeled proteins or from radioactivity peaks in radiolabeled experiments.

Blood samples. Blood samples for hematocrit and platelet count were obtained at the beginning and end of each experiment. The ACT and the activated partial thromboplastin time (aPTT) (Vet Reference Lab, Dallas, TX) were determined during the control period, 5 min after the administration of heparin, MCI-9038, SQ29548, ketanserin or placebo, or at least every $20 \mathrm{~min}$ if no drug was administered. Blood levels of MCI-9038 or heparin were derived from a standard curve of aPTT generated with known concentrations of MCI-9038 or heparin in fresh blood. The whole blood aPTT was performed using a mechanical fibrometer. $100-\mu 1$ samples of citrate (3.8\%)-anticoagulated arterial blood were incubated with known concentrations of MCI-9038 $(0.0025-250 \mu \mathrm{M})$ or heparin $(0.01-100 \mathrm{U} / \mathrm{ml})$ and platelet factor III reagent plus activator (Organon-Teknika, Durham, NC) at $37^{\circ} \mathrm{C}$. After $3 \mathrm{~min}$, calcium chloride $(0.025 \mathrm{M}, 100 \mu \mathrm{l})$ was added to the sample and the fibrometer clotting time was measured with an automatic timer.

Statistical analysis. All values are reported as the mean \pm SEM. The effect of treatment with respect to time was compared by a one-way analysis of variance (ANOVA). Paired, two-tailed $t$ tests were used to compare the effect of treatment and time within each group and to 
compare the hematocrit, platelet counts, and coagulation level before and after treatment. Fisher's exact test was used to compare treatment efficacy between heparin and MCI-9038 in groups I and II. A $P$ value $<0.05$ was considered significant.

\section{Results}

\section{Hemodynamics}

The hemodynamic record from control, group I, and group II dogs is listed in Table I. The heart rates, blood pressures, and frequency and severity of CFVs in the control dogs were stable during a $5 \mathrm{~h}$ period of observation (Fig. 1). Placebo injections of normal saline had no effect on hemodynamics or coronary blood flow.

\section{Effect of treatment}

Group I. After 30 min of CFVs, treatment with heparin (average initial dose $444 \pm 71 \mathrm{U} / \mathrm{kg}$; range, 200 to $1,000 \mathrm{U} / \mathrm{kg}$ ) abolished CFVs in 12 of 18 dogs (66\%) (Fig. 2), and treatment with MCI-9038 (average initial dose $1.96 \pm 0.86 \mathrm{mg} / \mathrm{kg}$; range, 0.5 to $7.0 \mathrm{mg} / \mathrm{kg}$ ) abolished CFVs in 5 of 7 dogs $(71 \%)(66$ vs. $71 \%, P$ $=$ NS) (Figs. 3 and 4). There was a significant decrease in both the frequency and severity of cyclic flow variations after treatment with either heparin or MCI-9038 (Table I). There were no significant hemodynamic effects related to the administration of either heparin or MCI-9038.

In five of six group I dogs observed for $4 \mathrm{~h}$ after cyclic flow variations were initially abolished by the administration of

Table I. Hemodynamics before and after Heparin or MCI-9038 in Group I and II Dogs

\begin{tabular}{|c|c|c|c|c|c|c|c|c|}
\hline & \multirow[b]{2}{*}{ HR } & \multirow[b]{2}{*}{ AOS } & \multirow[b]{2}{*}{ AOD } & \multicolumn{2}{|c|}{ Phasic flow } & \multicolumn{2}{|c|}{ Mean flow } & \multirow{2}{*}{$\begin{array}{c}\text { Frequency } \\
\text { of CFVs } \\
\text { (per } 30 \mathrm{~min} \text { ) }\end{array}$} \\
\hline & & & & Peak & Nadir & Peak & Nadir & \\
\hline & beats/min & \multicolumn{2}{|c|}{$m m H g$} & \multicolumn{4}{|c|}{$\%$ Control } & \\
\hline \multicolumn{9}{|c|}{ Control group $(n=5)$} \\
\hline Control & $129 \pm 10$ & $111 \pm 8$ & $90 \pm 9$ & 100 & & 100 & & 0 \\
\hline Sten & $129 \pm 11$ & $107 \pm 8$ & $87 \pm 8$ & $46 \pm 7^{*}$ & & $66 \pm 9$ & & 0 \\
\hline CFV $(1 h)$ & $128 \pm 13$ & $107 \pm 6$ & $88 \pm 6$ & $99 \pm 7$ & $5 \pm 1^{*}$ & $143 \pm 13$ & $5 \pm 1^{*}$ & $5.8 \pm 5$ \\
\hline CFV $(2 h)$ & $127 \pm 9$ & $113 \pm 4$ & $86 \pm 7$ & $113 \pm 7$ & $9 \pm 4^{*}$ & $170 \pm 5^{*}$ & $11 \pm 4^{*}$ & $5.7 \pm 0.7$ \\
\hline CFV $(3 h)$ & $125 \pm 7$ & $120 \pm 6$ & $89 \pm 6$ & $116 \pm 8$ & $7 \pm 2 *$ & $165 \pm 2^{*}$ & $11 \pm 2^{*}$ & $5.5 \pm 0.4$ \\
\hline CFV $(4 h)$ & $123 \pm 7$ & $113 \pm 6$ & $80 \pm 7$ & $113 \pm 8$ & $8 \pm 2 *$ & $161 \pm 14$ & $10 \pm 3^{*}$ & $5.3 \pm 0.6$ \\
\hline CFV $(5 h)$ & $122 \pm 7$ & $112 \pm 8$ & $84 \pm 7$ & $112 \pm 9$ & $8 \pm 2 *$ & $154 \pm 13$ & $12 \pm 4^{*}$ & $5.2 \pm 0.5$ \\
\hline \multicolumn{9}{|c|}{ Group IA (30 min/heparin) $(n=18)$} \\
\hline Control & $136 \pm 4$ & $116 \pm 4$ & $94 \pm 4$ & 100 & & 100 & & 0 \\
\hline Sten & $132 \pm 4$ & $113 \pm 4$ & $94 \pm 4$ & $55 \pm 5^{*}$ & & $70 \pm 6^{*}$ & & 0 \\
\hline CFV (30 min) & $127 \pm 4$ & $114 \pm 3$ & $92 \pm 3$ & $96 \pm 6$ & $15 \pm 2 *$ & $125 \pm 8$ & $19 \pm 3^{*}$ & $6.0 \pm 0.5$ \\
\hline Heparin & $122 \pm 4$ & $114 \pm 3$ & $90 \pm 3$ & $87 \pm 6$ & $58 \pm 8^{* \ddagger}$ & $104 \pm 9$ & $68 \pm 10^{\ddagger}$ & $1.8 \pm 0.7^{\ddagger}$ \\
\hline \multicolumn{9}{|c|}{ Group IB (30 $\mathrm{min} / \mathrm{MCI}-9038)(n=7)$} \\
\hline Control & $142 \pm 9$ & $131 \pm 9$ & $110 \pm 8$ & 100 & & 100 & & 0 \\
\hline Sten & $136 \pm 11$ & $133 \pm 8$ & $108 \pm 8$ & $64 \pm 5^{*}$ & & $79 \pm 3^{*}$ & & 0 \\
\hline $\mathrm{CFV}(30 \mathrm{~min})$ & $131 \pm 8$ & $129 \pm 9$ & $105 \pm 9$ & $106 \pm 14$ & $20 \pm 7^{*}$ & $136 \pm 12$ & $21 \pm 7^{*}$ & $5.7 \pm 0.8$ \\
\hline MCI-9038 & $139 \pm 19$ & $128 \pm 9$ & $101 \pm 8$ & $98 \pm 16$ & $56 \pm 14^{\ddagger}$ & $118 \pm 27$ & $58 \pm 15^{\ddagger}$ & $1.8 \pm 1.2^{\ddagger}$ \\
\hline \multicolumn{9}{|c|}{ Group IIA ( $3 \mathrm{~h} /$ heparin $)(n=7)$} \\
\hline Control & $152 \pm 7$ & $122 \pm 4$ & $100 \pm 3$ & 100 & & 100 & & 0 \\
\hline Sten & $143 \pm 9$ & $115 \pm 8$ & $96 \pm 7$ & $50 \pm 5^{*}$ & & $68 \pm 5^{*}$ & & $\mathbf{0}$ \\
\hline CFV $(1 h)$ & $133 \pm 9$ & $112 \pm 4$ & $95 \pm 4$ & $118 \pm 20$ & $7 \pm 2 *$ & $150 \pm 24$ & $8 \pm 2 *$ & $5.2 \pm 0.6$ \\
\hline CFV $(2 h)$ & $127 \pm 6^{*}$ & $113 \pm 4$ & $91 \pm 4$ & $115 \pm 21$ & $6 \pm 2^{*}$ & $149 \pm 29$ & $8 \pm 2^{*}$ & $5.4 \pm 0.5$ \\
\hline $\operatorname{CFV}(3 h)$ & $127 \pm 7^{*}$ & $116 \pm 4$ & $91 \pm 5$ & $108 \pm 18$ & $11 \pm 5^{*}$ & $137 \pm 25$ & $14 \pm 6^{*}$ & $5.9 \pm 0.6$ \\
\hline Heparin & $135 \pm 9$ & $114 \pm 5$ & $89 \pm 4$ & $115 \pm 21$ & $20 \pm 7^{* \ddagger}$ & $143 \pm 26$ & $28 \pm 10^{* \neq}$ & $5.4 \pm 0.8$ \\
\hline \multicolumn{9}{|c|}{ Group IIB (3 h/MCI-9038) $(n=7)$} \\
\hline Control & $144 \pm 8$ & $132 \pm 4$ & $98 \pm 6$ & 100 & & 100 & & 0 \\
\hline Sten & $143 \pm 8$ & $135 \pm 4^{\S}$ & $104 \pm 4$ & $65 \pm 8^{*}$ & & $86 \pm 7^{*}$ & & 0 \\
\hline CFV $(1 h)$ & $136 \pm 8$ & $128 \pm 2^{\S}$ & $100 \pm 4$ & $91 \pm 9$ & $5 \pm 1$ & $126 \pm 14$ & $3 \pm 1^{*}$ & $6.0 \pm 0.4$ \\
\hline CFV $(2 h)$ & $136 \pm 8$ & $132 \pm 3^{8}$ & $101 \pm 5$ & $100 \pm 10$ & $8 \pm 2 *$ & $135 \pm 13$ & $10 \pm 3^{*}$ & $5.7 \pm 0.3$ \\
\hline CFV $(3 h)$ & $134 \pm 7$ & $135 \pm 2^{\S}$ & $101 \pm 4$ & $98 \pm 8$ & $10 \pm 2 *$ & $132 \pm 11$ & $11 \pm 3^{*}$ & $5.4 \pm 0.4$ \\
\hline MCI-9038 & $139 \pm 7$ & $139 \pm 2^{8}$ & $97 \pm 5$ & $97 \pm 8$ & $25 \pm 11^{*}$ & $127 \pm 14$ & $28 \pm 11^{*}$ & $4.2 \pm 0.9$ \\
\hline
\end{tabular}

AOD, arterial diastolic pressure; AOS, arterial systolic pressure; HR, heart rate. Phasic flow, phasic coronary blood flow as percent control; mean flow, mean coronary blood flow as percent control; peak, average high flow during CFVs; nadir, average low flow during CFVs; frequency, number of CFVs per $30 \mathrm{~min}$; control, time period before constrictor placement with chest open; Sten, time period after constrictor placed on artery; CFV (30 min), 30 min of CFVs before treatment; CFV $(1-3 \mathrm{~h}), 1-3 \mathrm{~h}$ of CFVs before treatment; heparin, after treatment with heparin; MCI-9038, after treatment with MCI-9038. ${ }^{*} P<0.05$ paired $t$ test vs. control time period within each group; ${ }^{\ddagger} P<0.05$ treatment effect paired $t$ test before and after treatment; ${ }^{\S} P<0.05$ one-way ANOVA of treatment group (Groups IA, IB, IIA, and IIB) effect vs. control group. 

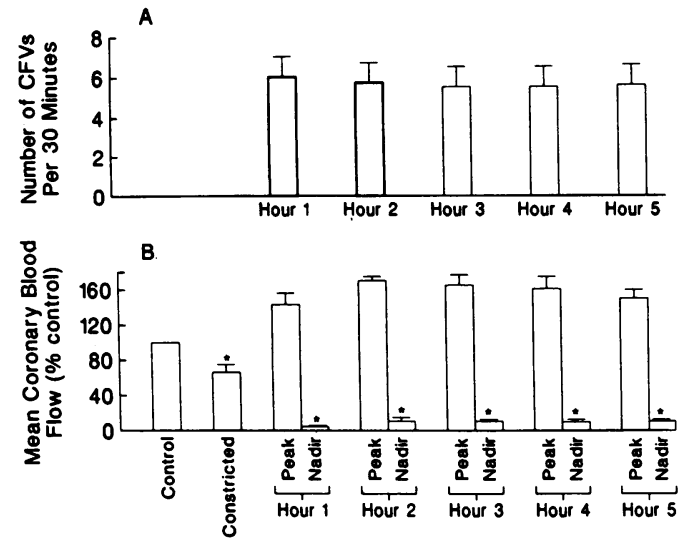

Figure 1. The $(A)$ frequency and severity of CFVs in control dogs $(n$ $=5$ ) was stable during a 5-h period of observation. $B$ shows the range of coronary blood flow variations. The constrictor reduced mean coronary blood flow to $66 \pm 9 \%$ of control values. ${ }^{*} P<0.05$ vs. control. ${ }^{*} P<0.05$.

heparin, CFVs recurred at an average time of $178 \pm 16 \mathrm{~min}$ despite continuous anticoagulation (ACT $>350 \mathrm{~s}$ ) (Fig. 5). CFVs did not recur in any dog during the first hour of observation.

Group II. After $3 \mathrm{~h}$ of CFVs, treatment with heparin (average initial dose $371 \pm 29 \mathrm{U} / \mathrm{kg}$ ) abolished CFVs in zero of seven dogs and treatment with MCI-9038 (average initial dose $3.29 \pm 0.36 \mathrm{mg} / \mathrm{kg}$ ) abolished CFVs in only one of seven dogs. Treatment with heparin after $3 \mathrm{~h}$ of CFVs did not result in a significant change in the frequency of CFVs but did cause a modest decrease in the severity of CFVs as measured by the nadir coronary blood flow (Table I). Treatment with MCI-9038 after $3 \mathrm{~h}$ of CFVs did not result in a significant change in the frequency or severity (nadir) of CFVs (Table $\mathrm{F}$ ); in these animals, we were unable to find a concentration of MCI-9038 that was protective. There were no significant hemodynamic effects related to treatment with heparin or MCI-9038 (Table I).

Group I vs. group II. Overall, inhibition of thrombin with either heparin or MCI-9038 abolished CFVs in 18 of 25 dogs (68\%) after 30 min of CFVs (group I) and in only 1 of 14 dogs (7\%) after $3 \mathrm{~h}$ of CFVs (group II) $(P<0.05$, Fisher's exact test) (Fig. 4). The treatment groups were equivalent during the time period before treatment with regard to the degree of stenosis (Table I), platelet count, and hematocrit (Table II). The doses of heparin or MCI-9038 were equivalent in all treatment groups (Figs. 6 and 7). The level of anticoagulation as measured by the ACT and the aPTT were equivalent in all treatment groups (Table II). In two dogs, we measured the blood level of MCI-9038 or heparin using the aPTT. The blood level of MCI-9038 at an ACT $>350$ was $0.25-2.5 \mu \mathrm{M}$ and the heparin level at an ACT > $350 \mathrm{~s}$ was $1.0-10 \mathrm{U} / \mathrm{ml}$. There was no significant change in platelet count or hematocrit during the course of observation. Systolic blood pressures were slightly higher in group IIB than in other groups, but this does not appear to have affected the overall results (Table I). Microscopic examination of cross-sections of the left anterior descending coronary artery at the site of the coronary constrictor obtained at the nadir of coronary blood flow revealed the presence of platelet-rich microaggregates in vessels harvested after both $30 \mathrm{~min}$ and $3 \mathrm{~h}$ of CFVs.

\section{Effect of a TXA $A_{2}$ receptor antagonist on CFVs}

In four dogs from group I and seven dogs from group II with persistent CFVs despite treatment with a thrombin inhibitor (heparin, $n=5$; MCI-9038, $n=6$ ), the effect of a $\mathrm{TXA}_{2} / \mathrm{PGH}_{2}$ receptor antagonist (SQ29548) was tested. In two of four group I dogs and in five of seven group II dogs, SQ29548 $(0.2 \mathrm{mg} / \mathrm{kg})$ abolished CFVs (Table III) without significant hemodynamic effect. Treatment with SQ29548 resulted in a marked decrease in the frequency and severity of CFVs (Fig. 8). There were no effects from placebo treatment in dogs with persistent CFVs.

\section{Effect of the combination of a TXA ${ }_{2} \mathrm{PGH}_{2}$ receptor antagonist and a serotonin receptor antagonist on persistent $C F V S$}

In four dogs with persistent CFVs despite treatment with either heparin or MCI-9038 and treatment with SQ29548, the effect of a serotonin receptor antagonist (ketanserin) was tested. 0.25 $\mathrm{mg} / \mathrm{kg}$ ketanserin abolished CFVs in all four dogs so treated. Ketanserin administration was associated with a modest decrease in arterial blood pressure, a slight decrease in the peak phasic coronary blood flow, and a marked increase in mean nadir coronary blood flow (Table III).

\section{Platelet aggregation}

The effects of MCI-9038 on platelet aggregation are recorded in Table IV. In PRP, MCI-9038 at concentrations as high as $2,000 \mu \mathrm{M}$ did not inhibit platelet aggregation in response to ADP $(5 \mu \mathrm{M})$ or U46619, the TX analogue $(1 \mu \mathrm{g} / \mathrm{ml})$. MCI-9038 inhibited thrombin-induced $(0.6 \mu \mathrm{M})$ platelet aggregation in a dose-dependent manner with an $\mathrm{IC}_{50}=0.2 \mu \mathrm{M}$

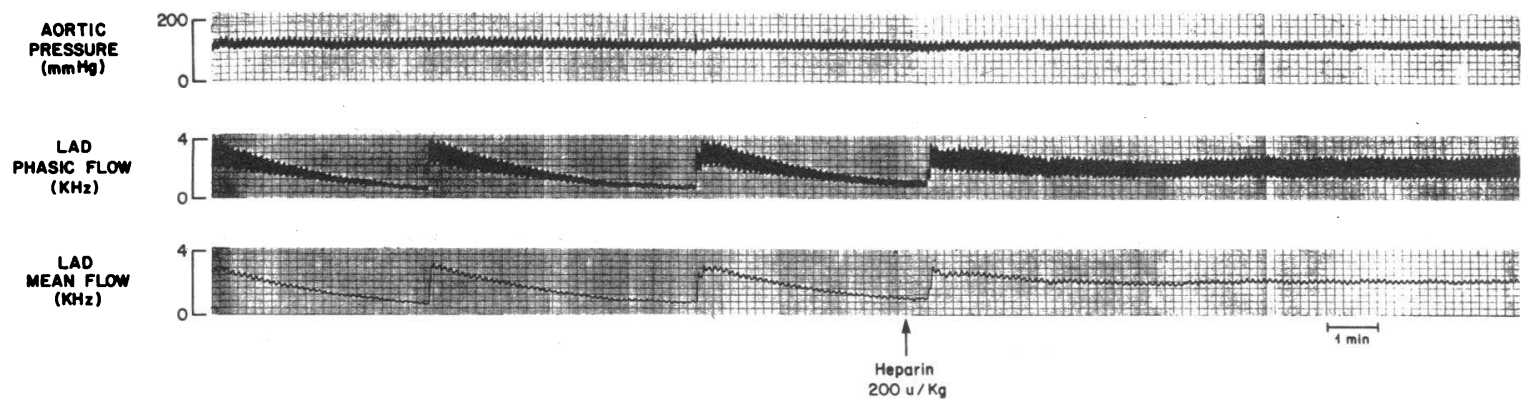

Figure 2. $200 \mathrm{U} / \mathrm{kg}$ heparin abolished CFVs when administered after $30 \mathrm{~min}$ of CFVs. LAD, left anterior descending coronary artery. Similar results were obtained in 12 of 18 group IA dogs. 


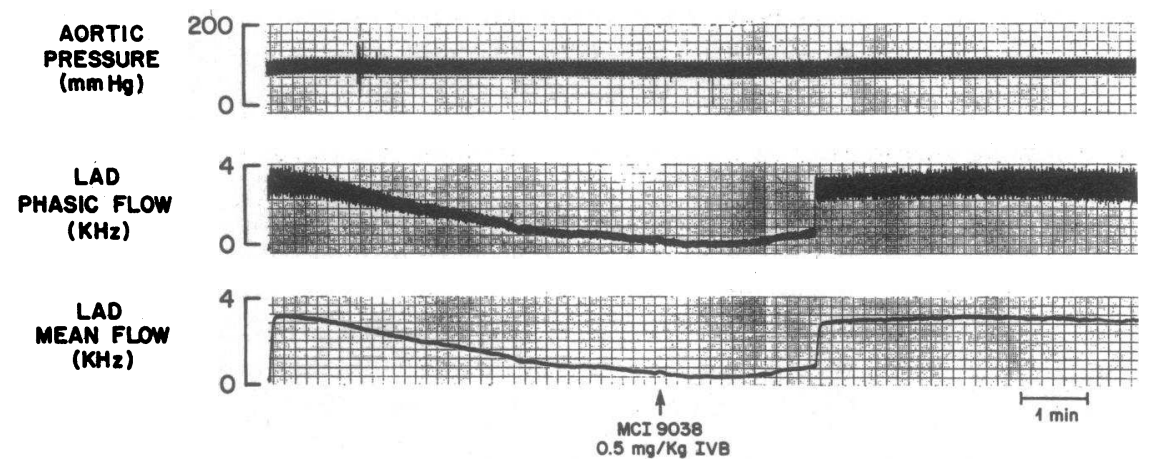

Figure 3. After $30 \mathrm{~min}$ of CFVs, $0.5 \mathrm{mg} / \mathrm{kg}$ MCI-9038 resulted in prompt abolition of CFVs. Similar results were observed in five of seven group IB dogs. IVB, intravenous bolus.
(Fig. 9). MCI-9038 also inhibited platelet aggregation in response to collagen $(5 \mu \mathrm{g} / \mathrm{ml})$ at a concentration 500 times greater than that required for inhibition of thrombin $\left(\mathrm{IC}_{50}\right.$ $=100 \mu \mathrm{M})$. Similar results were obtained with washed platelets with the exception that ADP did not induce aggregation of washed platelets at the doses tested. The effects of heparin on platelet aggregation are recorded in Table IV. In PRP, heparin $(1.0 \mathrm{U} / \mathrm{ml})$ inhibited platelet aggregation in response to thrombin $(0.6 \mathrm{U} / \mathrm{ml})$, but did not inhibit the response to ADP $(5 \mu \mathrm{M})$. Heparin did inhibit platelet aggregation in response to collagen $(5 \mu \mathrm{g} / \mathrm{ml})$ at a concentration of $20 \mathrm{U} / \mathrm{ml}$. In washed platelet suspensions, heparin $\left(\mathrm{IC}_{50}=1 \mathrm{U} / \mathrm{ml}\right)$ inhibited the aggregation of platelets in response to thrombin $(0.6 \mathrm{U} / \mathrm{ml})$. In addition, heparin $\left(\mathrm{IC}_{50}=10.0 \mathrm{U} / \mathrm{ml}\right)$ inhibited the aggregation of platelets in response to collagen $(5 \mu \mathrm{g} / \mathrm{ml})$.

We were unable to detect any differences between the aggregation responses to ADP or thrombin of platelets obtained from venous blood or from the coronary artery distal to the site of the stenosis. In addition, platelets obtained during the control period, during the initial $30 \mathrm{~min}$ of CFVs, and after $3 \mathrm{~h}$ of CFVs were equally responsive to ADP, collagen, and thrombin, and were inhibited by MCI-9038 or heparin to an equivalent degree.

\section{Thrombin- ${ }^{125}$ I-ATIII complex formation}

Prolonged incubation of dog plasma with ${ }^{125} \mathrm{I}$-ATIII did not result in the formation of thrombin- ${ }^{125}$ I-ATIII complexes as assessed by SDS-PAGE. We interpreted this finding to mean that the level of free thrombin in the circulation, if any, was below the level of detection in our assay. When thrombin was added directly to plasma containing ${ }^{125} \mathrm{I}-\mathrm{ATIII}$, thrombin- ${ }^{125} \mathrm{I}$ ATIII complexes were formed in a time-dependent manner

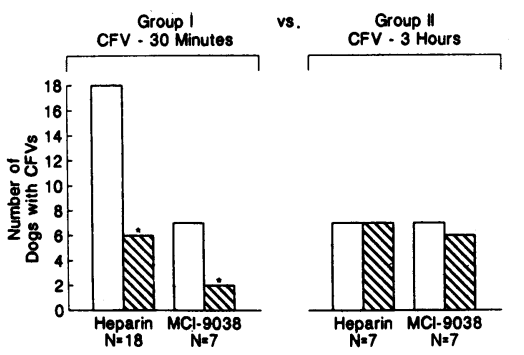

Figure 4. Effect of thrombin inhibitors on CFVs. After 30 min of CFVs (left), treatment with heparin abolished CFVs in 12 of 18 dogs and MCI-9038 abolished CFVs in 5 of 7 dogs. After 3 h of CFVs (right), heparin did not abolish CFVs in any

dogs and MCI-9038 abolished CFVs in one of seven dogs. ${ }^{*} P<0.05$ by Fisher's exact test effect of treatment, $30 \mathrm{~min}$ vs. $3 \mathrm{~h}$. $\square$, before treatment; $\mathbb{\otimes}$, after treatment. with maximum complex formation at $45 \mathrm{~min}$. Parallel experiments that measured thrombin- ${ }^{125}$ I-ATIII complex formation when thromboplastin and calcium ions were added to plasma containing ${ }^{125}$ I-ATIII resulted in the formation of complexes of the same molecular weight as in the previous experiment with purified components, as well as higher molecular weight
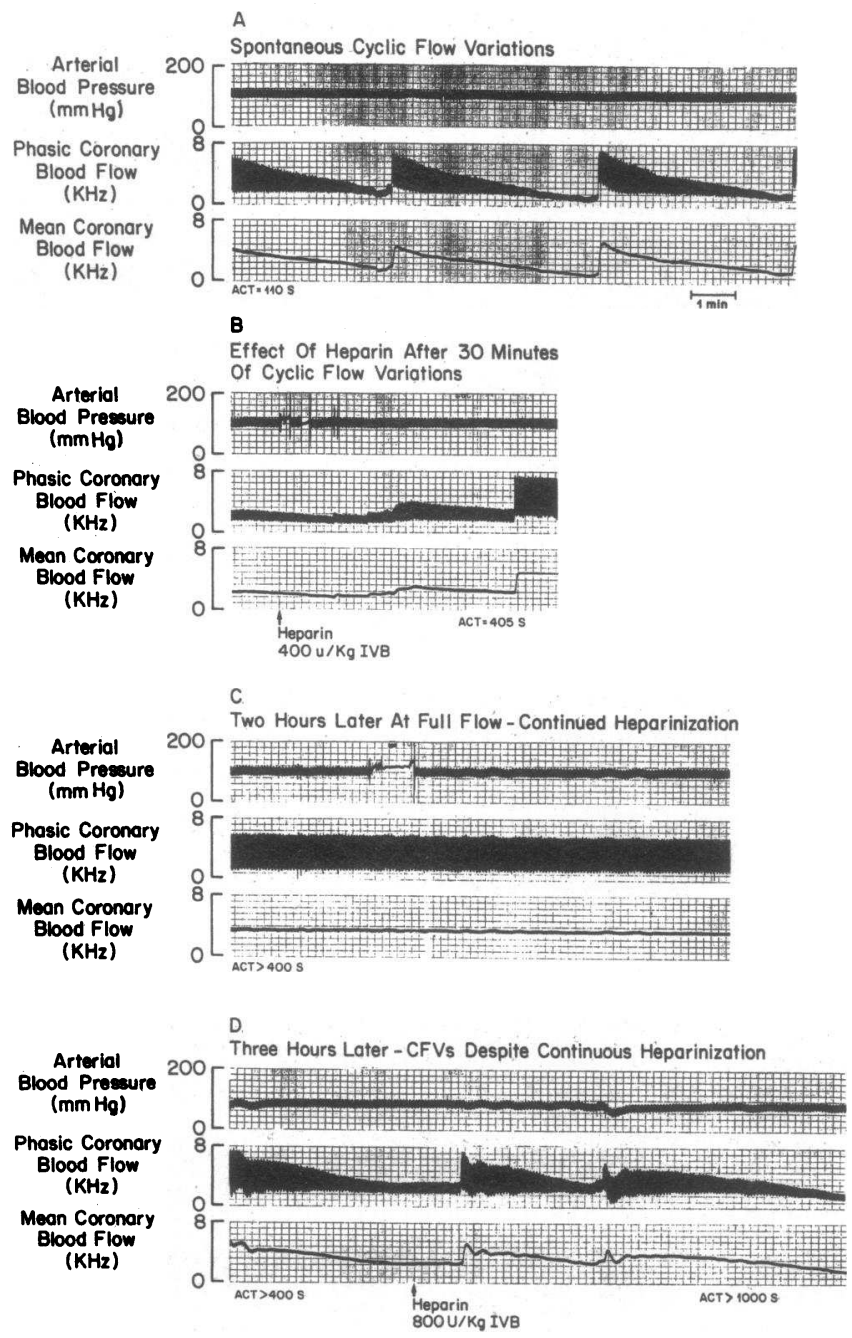

Figure 5. Recurrent CFVs. $(A)$ CFVs observed for $30 \mathrm{~min}$. (B) Treatment with heparin sufficient to prolong the ACT $>350 \mathrm{~s}$ abolished CFVs. (C) CFVs remained abolished for at least $2 \mathrm{~h}$. (D) CFVs recurred after $3 \mathrm{~h}$ and were resistant to abolition with additional heparin. 


\begin{tabular}{|c|c|c|c|c|c|c|c|c|}
\hline & \multicolumn{4}{|c|}{ Before treatment } & \multicolumn{4}{|c|}{ After treatment } \\
\hline & HCT & PLT & ACT & aPTT & HCT & PLT & ACT & aPTT \\
\hline Control $(n=5)$ & $37 \pm 3$ & $243 \pm 42$ & $95 \pm 2$ & $11 \pm 1$ & $37 \pm 3$ & $183 \pm 17$ & $97 \pm 1$ & $11 \pm 2$ \\
\hline Group IA (30 $\min$ hep) $(n=18)$ & $36 \pm 1$ & $186 \pm 19$ & $98 \pm 2$ & $12 \pm 1$ & $35 \pm 2$ & $198 \pm 27$ & $>400^{*}$ & $>90^{*}$ \\
\hline Group IB $(30 \min \mathrm{MCI})(n=7)$ & $38 \pm 2$ & $173 \pm 32$ & $100 \pm 2$ & $12 \pm 1$ & $35 \pm 1$ & $172 \pm 37$ & $>400^{*}$ & $>90^{*}$ \\
\hline Group IIA ( $3 h$ hep) $(n=7)$ & $39 \pm 1$ & $146 \pm 16$ & $98 \pm 2$ & $11 \pm 1$ & $39 \pm 2$ & $185 \pm 28$ & $>400^{*}$ & $>90^{*}$ \\
\hline Group IIB $(3 h \mathrm{MCI})(n=7)$ & $36 \pm 5$ & $257 \pm 8$ & $101 \pm 2$ & $12 \pm 1$ & $30 \pm 3$ & $222 \pm 11$ & $>400^{*}$ & $>90^{*}$ \\
\hline
\end{tabular}

Comparison of treatment groups before (during control period) and after treatment (end of observation period) with heparin or MCI-9038. HCT, hematocrit; PLT, platelet count $\times 10^{3}$. ${ }^{*} P<0.05$.

species $\left(160 M_{\mathrm{r}}\right)$, which may represent aggregates of ATIII in addition to complex formation (35). When heparin was added to plasma $(10 \mathrm{U} / \mathrm{ml})$ containing ${ }^{125} \mathrm{I}$-ATIII, the rate of complex formation was accelerated with maximum amounts of complex present after $15 \mathrm{~min}$. When MCI-9038 $(25 \mu \mathrm{g} / \mathrm{ml})$ was incubated with plasma containing ${ }^{125} \mathrm{I}$-ATIII, the addition of tissue thromboplastin and calcium ions failed to produce visible clot formation and no thrombin-125I-ATIII complexes were identified by SDS-PAGE. When thrombin instead of thromboplastin and calcium ions was added to plasma containing ${ }^{125} \mathrm{I}-\mathrm{ATIII}$ and MCI-9038 $(25 \mu \mathrm{g} / \mathrm{ml})$, visible formation was not identified and no thrombin- ${ }^{125}$ I-ATIII complexes could be demonstrated by SDS-PAGE. MCI-9038 inhibited the formation of thrombin-125I-ATIII complexes in a dose-dependent manner when added to plasma containing ${ }^{125}$ I-ATIII and exogenous thrombin. Complex formation was completely inhibited at concentrations of MCI-9038 >50 $\mu \mathrm{g} / \mathrm{ml}$. There was no evidence of inhibition of complex formation at concentrations $<10 \mu \mathrm{g} / \mathrm{ml}$ (Fig. 10). Plasma samples obtained from dogs 30-45 min after the intravenous administration of MCI-9038 inhibited the formation of thrombin- ${ }^{125}$ I-ATIII complexes in response to the in vitro addition of thrombin and ${ }^{125}$ I-ATIII, which paralleled the prolongation of the ACT and the aPTT as well as the inhibition of the formation of visible clot.

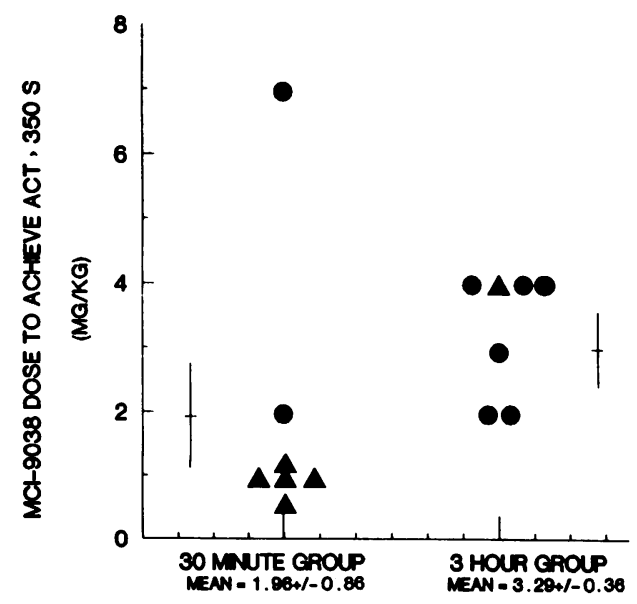

Figure 6. MCI-9038 dose response. The total dose of MCI-9038 required to achieve an ACT $>350 \mathrm{~s}$ is recorded ( $y$-axis) for each $\operatorname{dog}$ in 30-min group and 3-h group ( $x$-axis). There was no significant difference between the mean dose of MCI-9038 in each group. $\triangle$, did abolish CFVs; •, did not abolish CFVs.

\section{Discussion}

The data from the current study support the contention that thrombin may be an important mediator of platelet aggregation in vivo and that the role of thrombin is highly time dependent. CFVs were abolished in most dogs after short periods (30 min) of CFVs, but not after longer time periods ( $3 \mathrm{~h}$ ). In the model that we have used, CFVs appear to result from the aggregation of platelets at the site of experimental coronary stenosis and subsequent dislodgement and embolization (6-8, 12). The abolition of CFVs is therefore a relative measure of the inhibition of in vivo platelet aggregation. The level of anticoagulation as measured by the prolongation of the ACT and the aPTT was used as an indirect measurement of the degree of inhibition of thrombin activity. Thus, it is probable that the inhibitory effect of heparin or MCI-9038 on the development of CFVs in this model was a result of the inhibition of platelet activation by thrombin.

The Folts animal model (7) is a well-established model of the development of cyclic coronary blood flow reductions that are believed to result primarily from the accumulation of obstructive platelet aggregates at the site of a man-made coronary artery stenosis and induced endothelial injury, and subsequent embolization $(6-8,12)$. In the present study and in previous reports (8), we and others (7), have demonstrated the presence of occlusive platelet-rich aggregates at the site of the coronary constrictor in arteries obtained at the nadir of coronary blood flow. We have also found that in cases of severe thrombocytopenia $(<30,000)$, CFVs do not develop despite severe coronary stenoses and endothelial injury (unpublished observations). It has also been shown that inhibition of platelet adhe-

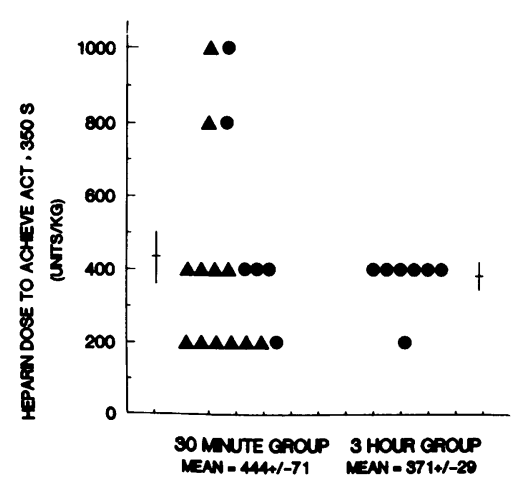

Figure 7. Heparin dose response. The total dose of heparin required to achieve an ACT $>350$ $s$ is recorded ( $y$-axis) for each dog in 30-min group and 3-h group $(x$ axis). There was no difference between the total dose of heparin in each group. $\triangle$, did abolish CFVs; •, did not abolish CFVs. 


\begin{tabular}{|c|c|c|c|c|c|c|c|c|}
\hline & \multirow[b]{2}{*}{ HR } & \multirow[b]{2}{*}{ AOS } & \multirow[b]{2}{*}{ AOD } & \multicolumn{2}{|c|}{ Phasic flow } & \multicolumn{2}{|c|}{ Mean flow } & \multirow{2}{*}{$\begin{array}{l}\text { Frequency } \\
\text { of CFVs }\end{array}$} \\
\hline & & & & Peak & Nadir & Peak & Nadir & \\
\hline & (beats/min) & \multicolumn{2}{|c|}{$m m H g$} & \multicolumn{4}{|c|}{$\%$ Control } & (no. per $30 \mathrm{~min}$ ) \\
\hline Before SQ29548 $(n=11)$ & $131 \pm 6$ & $131 \pm 5$ & $100 \pm 4$ & $107 \pm 13$ & $20 \pm 5$ & $140 \pm 17$ & $22 \pm 7$ & $4.4 \pm 1$ \\
\hline After SQ29548 $(n=11)$ & $130 \pm 6$ & $128 \pm 5$ & $94 \pm 4^{*}$ & $105 \pm 13$ & $71 \pm 12^{*}$ & $128 \pm 17$ & $86 \pm 13^{*}$ & $1.1 \pm 0.6^{*}$ \\
\hline Before ketans (in combination with SQ29548) $(n=4)$ & $128 \pm 10$ & $126 \pm 11$ & $101 \pm 10$ & $118 \pm 29$ & $29 \pm 6$ & $147 \pm 39$ & $40 \pm 9$ & $3 \pm 1$ \\
\hline After ketans (in combination with SQ29548) $(n=4)$ & $128 \pm 13$ & $104 \pm 9^{*}$ & $81 \pm 8^{*}$ & $78 \pm 20^{*}$ & $78 \pm 20$ & $77 \pm 12$ & $77 \pm 12^{*}$ & $0^{*}$ \\
\hline
\end{tabular}

Ketans, ketanserin, a serotonin receptor antagonist; $\mathrm{SQ} 29548, \mathrm{TXA}_{2} / \mathrm{PGH}_{2}$ receptor antagonist. $n=11 ;{ }^{*} P<0.05$. For other abbreviations, see Table I.

sion with a MAb to the glycoprotein IIb/IIIa receptor prevents CFVs in most cases (36). Finally, the finding that inhibition of serotonin receptor activation (10-12) or the inhibition of TXA $_{2}$ synthesis (8) or receptor activation (9) abolishes CFVs in most dogs supports the conclusion that platelet aggregation plays a fundamental role in the phenomenon of CFVs in this model. In the animal model that we have used, great caution must be exercised to avoid significant intersubject variations and to maintain uniform standards governing the surgical preparation, including the severity of coronary constriction and reproducibility of consistent CFVs. Despite the acknowledged limitations of this animal model, it does provide an important means for studying the complex factors governing in vivo intracoronary platelet-thrombus formation.

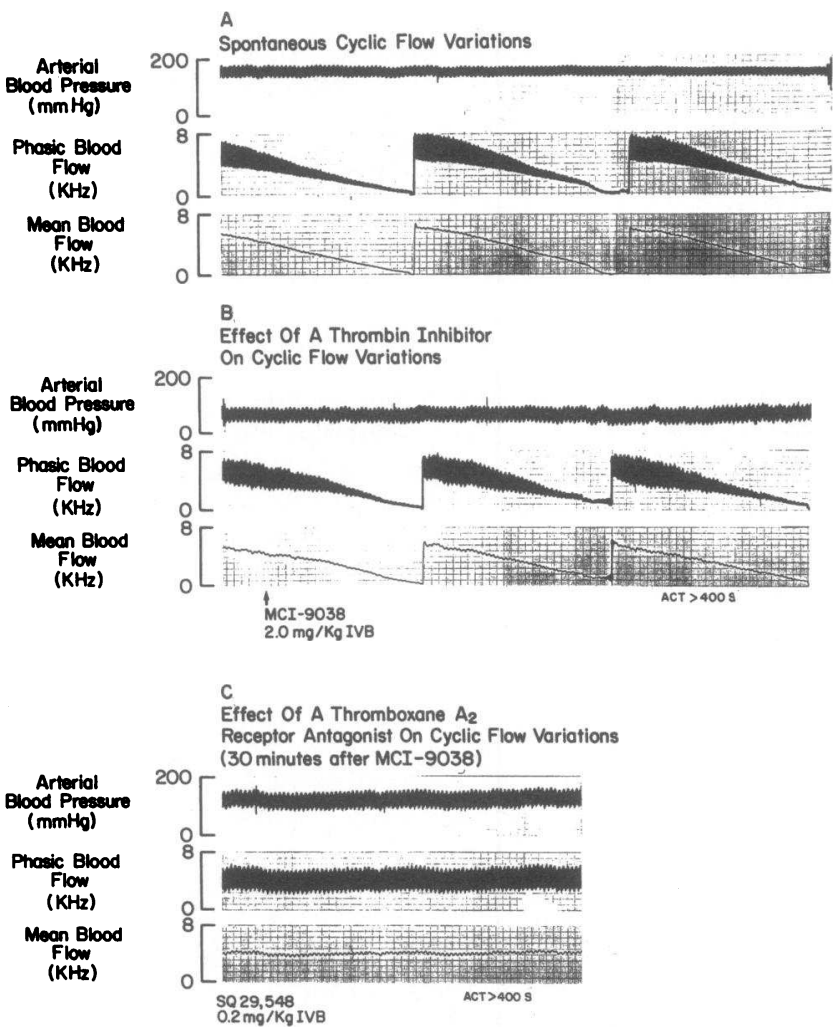

Figure 8. After 30 min of CFVs $(A)$, treatment with MCI-9038 (B) did not abolish CFVs. In $C$, SQ29548 abolished CFVs promptly. Similar results were observed in 7 of 11 dogs.
Although the occurrence of CFVs in this model appears to be primarily a platelet-dependent phenomenon, we do not discount the importance of other factors that may contribute to the reduction in coronary blood flow. We have shown that enhanced vasoconstriction at the site of platelet accumulation, apparently due to the local release of platelet-derived vasoactive substances, including serotonin and $\mathrm{TXA}_{2}$, may contribute to the reduction in coronary blood flow in this model (37). In addition, leukocytes and other mediators of inflammation and the generation of fibrin clot may also be involved.

MCI-9038 is the most potent and selective member of a family of recently synthesized thrombin inhibitors (21). In other animal models, it has been demonstrated that its antithrombotic effect is independent of ATIII (38). In humans, it has been used for anticoagulation during cardiopulmonary bypass (39) and hemodialysis (40) and for the treatment of disseminated intravascular coagulation (39). Its use has not been associated with platelet activation or thrombocytopenia (41) and MCI-9038 does not inhibit plasmin to any significant degree (21). In a rat model of cerebral microcirculation thromboembolism, MCI-9038 was found to inhibit the formation of occlusive platelet aggregates (42).

MCI-9038 is a substituted arginine derivative with three binding regions that correspond to $(a)$ a positively charged guanidino group, $(b)$ an aromatic $\mathrm{N}^{2}$-substituent, and $(c)$ a hydrophobic carboxamide portion (22). The specificity of MCI-9038 for thrombin has been shown to be dependent on a stereospecific interaction between the carboxamide substituent of MCI-9038 and a hydrophobic binding pocket on thrombin (22). The doses used in this experiment resulted in circulating blood levels of MCI-9038 (0.25-2.5 $\mu \mathrm{M})$ well within the thrombin sensitive range, and it is unlikely that the inhibition of other proteases was responsible for the effects observed.

Evidence from this study confirms the ability of MCI-9038 to inhibit thrombin. MCI-9038 prolonged the standard

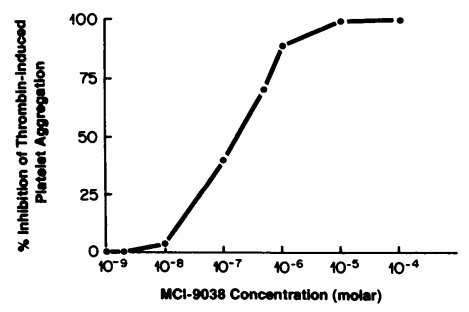

Figure 9. MCI-9038 inhibited thrombin-induced $(0.6$ $\mathrm{NIH}$ units/ml) aggregation of washed canine platelets in a dose-dependent manner when added before the addition of thrombin. The $\mathrm{IC}_{\mathbf{5 0}}$ for MCI-9038 was $\mathbf{0 . 2}$ $\times 10^{-6} \mathrm{M}$. 
Table IV. Platelet Aggregation in the Presence of MCI-9038 or Heparin

\begin{tabular}{|c|c|c|c|}
\hline \multirow[b]{2}{*}{ Agonist } & \multirow[b]{2}{*}{ Dose } & \multicolumn{2}{|c|}{ MCI-9038 IC 50} \\
\hline & & PRP & Washed platelets \\
\hline & & \multicolumn{2}{|c|}{$\mu M$} \\
\hline Thrombin & $0.6 \mathrm{U} / \mathrm{ml}$ & 0.2 & 0.2 \\
\hline Collagen & $5 \mu \mathrm{g} / \mathrm{ml}$ & 100 & 200 \\
\hline ADP & $5 \mu \mathrm{M}$ & $>2,000$ & DNA* \\
\hline \multirow[t]{3}{*}{ U46619 } & $1 \mu \mathrm{g} / \mathrm{ml}$ & $>2,000$ & NT \\
\hline & & \multicolumn{2}{|c|}{ Heparin $I C_{s 0}$} \\
\hline & & \multicolumn{2}{|c|}{$U / m l$} \\
\hline Thrombin & $0.6 \mathrm{U} / \mathrm{ml}$ & 1.0 & 1.0 \\
\hline Collagen & $5 \mu \mathrm{g} / \mathrm{ml}$ & 20 & 10 \\
\hline ADP & $5 \mu \mathrm{M}$ & $>100$ & DNA \\
\hline
\end{tabular}

Dose of agonist is minimum dose required to achieve maximal percent light transmission; U46619, TXA 2 analogue: DNA, washed platelets did not aggregate in response to ADP at any dose tested. See text for range of agonist doses; NT, U46619 not tested.

thrombin-dependent tests of blood coagulation (ACT, aPTT) in a dose-dependent manner. It has been demonstrated in humans that the prolongation of the ACT correlated with plasma levels of MCI-9038 (39). MCI-9038 also inhibited the aggregation of canine platelets in response to thrombin in a dose-dependent manner $\left(\mathrm{IC}_{50}=0.2 \mu \mathrm{M}\right)$. While MCI-9038 also inhibited the aggregation of platelets in response to collagen, the $\mathrm{IC}_{50}$ was $\sim 500-1,000$ times greater than that needed to inhibit thrombin and significantly higher than the circulating drug levels observed. Furthermore, MCI-9038 prevented the formation of thrombin-ATIII complexes, as demonstrated by gel electrophoresis. The ability of MCI-9038 to inhibit CFVs in this canine model thus appears to be linked to the inhibition of thrombin.

Heparin is a heterogeneous, polydisperse glycosoaminoglycan with a molecular mass range from 3,000 to $30,000 \mathrm{D}$ (43). Commercial preparations are usually produced by extraction from porcine intestinal mucosa or bovine lung. The principal mode of action of heparin is thought to be the enhancement of the antiprotease activity of ATIII (44). The effect of the antithrombin/heparin system may be mediated through either $(a)$ the inhibition of thrombin or $(b)$ the inhibition of the catalysis of prothrombin to thrombin (45). The inhibition of thrombin not only blocks the conversion of fibrinogen to fibrin monomer, but also prevents the thrombindependent activation of factor V (44). Activated factor V (Va) combines with Factor $\mathrm{Xa}$ on the platelet surface membrane to form the prothrombinase complex, which catalyzes the conversion of prothrombin to thrombin (45). The prompt inhibition of the activation of Factor $\mathrm{V}$ effectively blocks the coagulation sequence before the generation of additional thrombin.

Heparin may also have an important inhibitor effect on platelet function that is independent of ATIII (46). Heparin, in the absence of ATIII, has been shown to inhibit thrombin-induced aggregation of washed rabbit platelets (47) and to inhibit thrombin-stimulated generation of platelet factor Va (48).
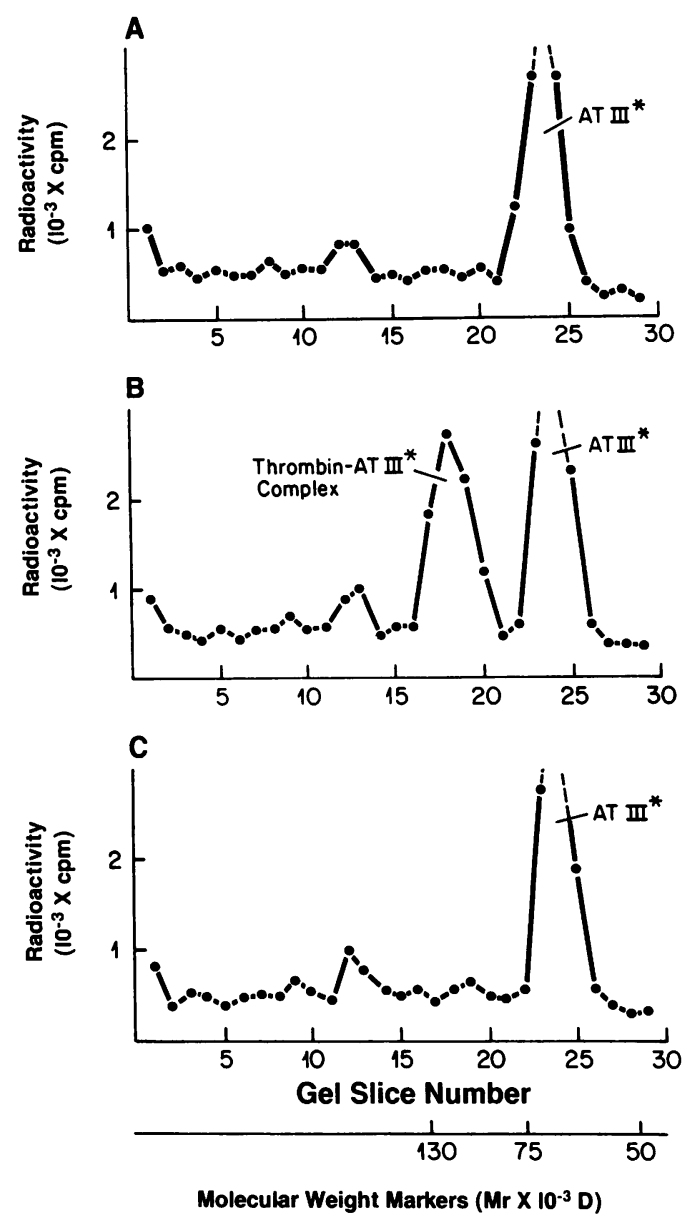

Figure 10. Thrombin-antithrombin complexes on SDS-PAGE. $(A)$ Radiolabeled ATIII migrated as a discrete band on gel electrophoresis (SDS-PAGE). A similar result was obtained when radiolabeled ATIII was added to dog plasma, indicating that thrombin is not detectable in plasma. $(B)$ Prolonged incubation of radiolabeled ATIII with thrombin resulted in the formation of two discrete bands: $(a)$ ATIII and $(b)$ thrombin-ATIII complexes at a higher molecular weight. The addition of thromboplastin to plasma to generate endogenous thrombin resulted in a similar result. $(C)$ The addition of MCI-9038 to radiolabeled ATIII before incubation with thrombin resulted in the inhibition of the formation of thrombin-ATIII complexes in a dose-dependent manner. The minimal inhibitor level of MCI-9038 was $25 \mu \mathrm{g} / \mathrm{ml}$.

Heparin may also induce a functional platelet defect at the level of the platelet membrane (49). The data from this study confirm the ability of heparin, in the absence of ATIII, to inhibit the activation of platelets by thrombin. Heparin also inhibited the aggregation of both washed platelets and PRP in response to collagen. The mechanism of this effect is not clear.

An RIA for the detection of circulating free thrombin has been described, but thrombin is ordinarily not detectable in plasma due primarily to its rapid inactivation by ATIII (50-52). A quantitative estimation of thrombin activity can be derived from the presence of thrombin-antithrombin complexes $(49,51)$. In comparison to the individual molecules, the thrombin-antithrombin complex possesses unique antigenic determinants that can be detected by immunoassay $(49,50)$, and it has a higher molecular weight on gel electrophoresis (42). In this experiment, we were unable to detect free throm- 
bin in either venous or coronary arterial blood until the addition of exogenous thromboplastin. Although thrombin appears to play an important role in mediating the development of cyclic flow variations, the effect seems localized to the specific area of arterial injury.

Although differing in their structure and mechanisms of action, heparin and MCI-9038 share the ability to inhibit thrombin $(19,21)$. Heparin acts primarily indirectly by enhancing the effect of ATIII (19), whereas MCI-9038 forms a 1:1 stoichiometric complex with thrombin that prevents its proteolytic and platelet-stimulating activities (21). That either heparin or MCI-9038 abolished CFVs after short periods of CFVs argues in favor of the conclusion that the inhibition of thrombin results in inhibition of platelet aggregation in this model. It is important to note that both heparin and MCI-9038 may have actions other than the inhibition of thrombin and that these actions may have played a role in the results observed in this experiment.

The explanation for the success of abolition of CFVs with either heparin or MCI-9038 after short but not prolonged periods of CFVs is not clear. The ability of either heparin or MCI-9038 to abolish CFVs after short but not prolonged time periods suggests that either thrombin inhibition is more difficult after long periods of CFVs and/or thrombin plays a less important role in mediating platelet aggregation after longer time intervals. Local accumulations of thrombin within the thrombus may be relatively resistant to inhibition by circulating inhibitors. It is also possible that other mediators of platelet activation, including collagen, TXA ${ }_{2}$ and ADP, achieve sufficient local concentration to mediate platelet aggregation even in the presence of thrombin inhibitors (18).

The results from this study support our previous findings that $\mathrm{TXA}_{2}$ and serotonin are important mediators of platelet aggregation and resultant CFVs in dogs with coronary artery stenosis and endothelial injury (8-12). The $\mathrm{TXA}_{2}$ receptor antagonist, SQ29548, and/or the serotonin receptor antagonist, ketanserin, abolished CFVs in every case in which thrombin inhibition with heparin or MCI-9038 failed to do so. The efficacy of treatment with SQ29548 and ketanserin was not related to the duration of CFVs before treatment.

In conclusion, the results from this study support the following hypotheses: (a) thrombin appears to be an important mediator of CFVs in a canine model of coronary artery stenosis and endothelial injury and $(b)$ the inhibition of thrombin, with either MCI-9038, or heparin, abolishes CFVs in most dogs after short but not prolonged periods of CFVs. These findings suggest that either thrombin plays a less important role in mediating platelet activation after prolonged periods of CFVs and/or that the inhibition of thrombin at the site of endovascular injury with heparin or MCI-9038 is more difficult at later times.

\section{Acknowledgments}

We wish to express our appreciation to Mary Hammond, Lacy Hill Eidt, and Nancy Dickey for their assistance in the preparation of this manuscript. We also acknowledge the assistance of Patricia Pastor in performing the statistical analyses.

This work was supported in part by National Heart, Lung, and Blood Institute Ischemic Specialized Centers of Research grant HL-17669 and the Moss Heart Fund, Dallas, TX.

\section{References}

1. Willerson, J. T., L. D. Hillis, M. Winniford, and L. M. Buja. 1986. Speculation regarding mechanisms responsible for acute ischemic heart disease syndromes. J. Am. Coll. Cardiol. 8:245-250.

2. Willerson, J. T., W. B. Campbell, M. D. Winniford, J. Schmitz, P. Apprill, B. G. Firth, J. Ashton, T. Smitherman, L. Bush, and L. M. Buja. 1984. Conversion from chronic to acute coronary artery disease: speculation regarding mechanisms. Am. J. Cardiol. 54:1349-1354.

3. Folts, J. D., K. Gallagher, and G. G. Rowe. 1982. Blood flow reductions in stenosed canine coronary arteries: vasospasm or platelet aggregation? Circulation. 65:248-255.

4. Fitzgerald, D. J., L. Roy, F. G. Catella, and G. A. Fitzgerald. 1986. Platelet activation in unstable coronary disease. N. Engl. J. Med. 315:983-989.

5. Fuster, V., and J. H. Chesebro. 1986. Mechanics of unstable angina. $N$. Engl. J. Med. 315:1023-1025.

6. Hirsh, P. D., L. D. Hillis, W. B. Campbell, B. G. Firth, and J. T. Willerson. 1981. Release of prostaglandins and thromboxane A2 into the coronary circulation in patients with ischemic heart disease. $N$. Engl. J. Med. 304:685-691.

7. Folts, J. D., E. B. Crowell, Jr., and G. G. Rowe. 1976. Platelet aggregation in partially obstructed vessels and its elimination with aspirin. Circulation. 54:365-370.

8. Bush, L. R., W. B. Campbell, L. M. Buja, G. D. Tilton, and J. T. Willerson. 1984. Effects of the selective thromboxane synthetase inhibitor dazoxiben on variations in coronary blood flow in stenosed canine coronary arteries. Circulation. 69:1161-1170.

9. Ashton, J., J. M. Schmitz, W. B. Campbell, M. L. Olgetree, S. Raheja, A. L. Taylor, C. Fitzgerald, L. M. Buja, and J. T. Willerson. 1986. Inhibition of cyclic flow variations in stenosed canine coronary arteries by thromboxane A2/prostaglandin $\mathrm{H} 2$ receptor antagonists. Circ. Res. 59:568-578.

10. Bush, L. R., W. B. Campbell, K. Kern, G. D. Tilton, P. Apprill, J. Ashton, J. Schmitz, L. M. Buja, and J. T. Willerson. 1984. The effects of alpha $a_{2}$-adrenergic and serotonergic receptor antagonists on cyclic blood flow alterations in stenosed canine coronary arteries. Circ. Res. 55:642-652.

11. Ashton, J., C. R. Benedict, C. Fitzgerald, S. Raheja, A. Taylor, W. B. Campbell, L. M. Buja, and J. T. Willerson. 1986. Serotonin is a mediator of cyclic flow variations in stenosed canine coronary arteries. Circulation. 73:572-578.

12. Ashton, J., M. L. Olgetree, I. M. Michel, P. Golino, J. M. McNatt, A. L. Taylor, A. Raheja, J. Schmitz, L. M. Buja, W. B. Campbell and J. T. Willerson. 1987. Cooperative mediation by serotonin S2 and thromboxane A2/prostaglandin $\mathrm{H} 2$ receptor activation of cyclic flow variations in dogs with severe coronary stenoses. Circulation. 76:952-959.

13. Fenton, J. W. 1986. Thrombin. Ann. NY. Acad. Sci. 485:5-15.

14. Harmon, J. T., and G. A. Jamieson. 1986. Platelet activation by alpha-thrombin is a receptor-mediated event. Ann. NY. Acad. Sci. 485:387-95.

15. Haver, V. M., and D. H. Namm. 1984. Characterization of the thrombin-induced contraction of vascular smooth muscle. Blood Vessels. 21:53-63.

16. Walz, D. A., G. F. Anderson, and J. W. Fenton II. 1986. Responses of aortic smooth muscle to thrombin and thrombin analogues. Ann. NY. Acad. Sci. 485:323-332.

17. Jungi, T. W., M. O. Spycher, U. E. Nydegger, and S. Barandum. 1986. Platelet-leukocyte interaction: selective binding of thrombinstimulated platelets to human monocytes, polymorphonuclear leukocytes, and related cell lines. Blood. 67:629-636.

18. Hubbell, J., and L. V. McIntire. 1986. Platelet active concentration profiles near growing thrombi. A mathematical consideration. Biophys. J. 50:937-945.

19. Rosenberg, R. D. 1975. Actions and interactions of antithrombin and heparin. N. Engl. J. Med. 292:146-151. 
20. Baruch, D., T. Lindhout, R. Wagenvoord, and H. C. Hemker. 1986. Inhibition of thrombin-catalyzed reactions in blood coagulation and platelet activation by heparin fractions in the absence of antithrombin III. Haemostasis. 16:71-81.

21. Okamoto, S., and A. Hijikata. 1981. Potent inhibition of thrombin by the newly synthesized arginine derivative No. 805 . The importance of stereo-structure of its hydrophobic carboxamide portion. Biochem. Biophys. Res. Commun. 101:440-446.

22. Kikumoto, R., Y. Tamao, T. Tezuka, S. Tonomura, H. Hara, K. Ninomiya, A. Hijikata, and S. Okamoto. 1984. Selective inhibition of thrombin by $(2 \mathrm{R}, 4 \mathrm{R})-4$-methyl-1-[N2-[(3-methyl-1,2,3,4-tetrahydro-8-quinolinyl)sulfonyl]-1-arginyl)]-2-piperidine carbocylic acid. Biochemistry. 23:85-90.

23. Hartley, C. J., H. G. Hanley, R. M. Lewis, and J. S. Cole. 1978. Synchronized pulsed doppler blood flow and ultrasound dimension measurement in conscious dogs. Ultrasound Med. Biol. 4:99-110.

24. Rodriguez, H. J., and A. J. Vanderweilen. 1979. Molecular weight determination of commercial heparin sodium USP and its sterile solutions. J. Pharm. Sci. 68:588-591.

25. Ogletree, M. L., D. N. Harris, R. Greenburg, M. F. Haslanger, and M. Nakane. 1984. Pharmacological actions of SQ29,548, a novel selective thromboxane antagonist. J. Pharmacol. Exp. Ther. 234:435.

26. DeClerck, F., J. David, and P. Janssen. 1982. Inhibition of 5-Hydroxytryptamine-induced and amplified human platelet aggregation by ketanserin $(\mathrm{R} 41,468)$, a selective $5-\mathrm{HT}_{2}$-receptor antagonist. Agents Actions. 12:388-392.

27. Bevan, J., and S. Heptinstall. 1983. Effects of ketanserin and mepyramine on platelet aggregation and on the uptake of 5-hydroxytryptamine into platelets. Thromb. Res. 30:415-420.

28. Aster, R. H., and J. H. Jandl. 1964. Platelet sequestration in man. I. Methods. J. Clin. Invest. 43:843-848.

29. Ardlie, N. G., M. A. Packham, and J. F. Mustard. 1970. Adenosine diphosphate-induced platelet aggregation in suspensions of washed rabbit platelets. Br. J. Haematol. 19:7-12.

30. Kinlough-Rathbone, R. L., M. A. Packham, and J. F. Mustard. 1986. Platelet aggregation. In Platelet Interactions with the Vessel Wall. J. Hawiger, editor. American Physiological Society, Bethesda, MD. 64 .

31. Weber, K., and M. Osborn. 1969. The reliability of molecular weight determinations by dodecyl sulfate-polyacrylamide gel electrophoresis. J. Biol. Chem. 244:4406-4412.

32. Rosenberg, R. D. 1975. The effect of heparin on factor XIa and plasmin Thromb. Diath. Haemorrh. 33:51-62.

33. Kurachi, K., K. Fujikawa, G. Schmer, and E. W. Davie. 1976. Inhibition of bovine factor IX $\mathrm{X}_{\alpha}$ and factor $\mathrm{X}_{\alpha \beta}$ by antithrombin III. Biochemistry. 15:373-377.

34. Odegard, O. R., M. Lie, and U. Abildgaard. 1975. Human cofactor activity measured with an amidolytic method. Thromb. Res. 6:287-294.

35. Marciniak, E., and G. Gora-Maslak. 1983. High molecular weight forms of antithrombin III complexes in blood. Thromb. Haemostatis. 49:32-36.

36. Coller, B. S., and L. E. Scudder. 1985. Inhibition of dog platelet function by in vivo infusion of $F\left(a b^{\prime}\right)_{2}$ fragments of a monoclonal antibody to the platelet glycoprotein IIb/IIIa receptor. Blood. 66:1456-1459.
37. Golino, P., J. Ashton, L. M. Buja, A. Taylor, and J. T. Willerson. 1987. Thromboxane and serotonin released by activated platelets vasoconstrict coronary arteries in vivo. Circulation. (Suppl.)76:1352A. (Abstr.)

38. Kumada, T., and Y. Abiko. 1981. Comparative study on heparin and synthetic thrombin inhibitor No. 805 (MD-805) in experimental antithrombin III-deficient animals. Thromb. Res. 24:285-298.

39. Kumon, K., K. Tanaka, N. Nakajima, Y. Naito, and T. Fujita. 1984. Anticoagulation with a synthetic thrombin inhibitor after cardiovascular surgery and for treatment of disseminated intravascular coagulation. Crit. Care Med. 12:1039-1043.

40. Matsuo, T., K. Nakao, T. Yamada, and O. Matsuo. 1986. Effect of a new anticoagulant (MD-805) on platelet activation in the hemodialysis circuit. Thromb. Res. 41:33-41.

41. Matsuo, T., K. Nakao, T. Yamada, and O. Matsuo. 1986. A new thrombin inhibitor MD805 and thrombocytopenia encountered with heparin hemodialysis. Thromb. Res. 44:247-251.

42. Yamamoto, T., T. Hirata, M. Inafaki, R. Kikumoto, Y. Tamao, and S. Okamoto. 1987. Effect of MCI-9038, a selective thrombin inhibitor, on cerebral microcirculation after cerebral ischemia in rats. Thromb. Res. 58:108-114.

43. Casu, B. 1984. Structure of heparins and their fragments. Nouv. Rev. Fr. D'Hematol. 26:211-219.

44. Bjork, I., and U. Lindahl. 1982. Mechanism of the anticoagulation action of heparin. J. Biol. Chem. 257:9487-9493.

45. Ofosu, F. A., P. Sie, G. J. Modi, F. Fernandez, M. R. Buchanan, M. A. Blajchman, B. Boneu, and J. Hirsh. 1987. The inhibition of thrombin-dependent positive-feedback reactions is critical to the expression of the anticoagulant effect of heparin. Biochem. J. 243:579588.

46. Saba, H. I., S. R. Saba, and G. A. Morelli. 1984. Effect of heparin on platelet aggregation. Am. J. Hematol. 17:295-306.

47. Cade, J. F., M. R. Buchanan, B. Boneu, P. Ockleford, C. J. Carter, A. L. Cerskus, and J. Hirsh. 1984. A comparison of the antithrombotic and hemorrhagic effects of low molecular weight heparin fractions: the influence of method of preparation. Thromb. Res. 35:613-625.

48. Baruch, D., J. Franssen, H. C. Hemker, and T. Lindhout. 1985. Effect of heparin and low molecular weight heparins on thrombin-induced blood platelet activation in the absence of antithrombin III. Thromb. Res. 38:447-458.

49. Buchanan, M. R., F. A. Ofosu, F. Fernandez, and J. VanRyn. 1986. Lack of relationship between enhanced bleeding induced by heparin and other sulfated polysaccharides and enhanced catalysis of thrombin inhibition. Semin. Thromb. Hemostasis. 12:324-327.

50. Fernandez, F., P. N'guyen, J. VanRyn, F. A. Ofosu, J. Hirsh, and M. R. Buchanan. 1986. Hemorrhagic doses of heparin and other glycosoaminoglycans induce a platelet defect. Thromb. Res. 43:491495.

51. Shuman, M. A., and P. W. Majerus. 1976. The measurement of thrombin in clotting blood by radioimmunoassay. J. Clin. Invest. 58:1249-1258.

52. Collen, D., and F. A. deCock. 1975. A tanned red cell haemagglutination inhibition immunoassay (TRCHII) for the quantitative estimation of thrombin-antithrombin complexes in human plasma. Thromb. Res. 7:235-238. 